مجلة جامعة سبها للعلوم البحتة والتطبيقية

Sebha University Journal of Pure \& Applied Sciences

Journal homepage: www.sebhau.edu.ly/journal/index.php/jopas

\title{
3D Hologram Technology in Libyan Educational Institutions in Future: Re-view
}

*Gharsa .A. Elmarash, Muna. M. Adrah, Entisar. E. Eljadi

Computer Science Department, Faculty of Science,Elmergib University, Libya

\section{Keywords:}

3DH (Three Dimensional

Hologram) Technology

Holography

Education

Holographic projection

learning

\begin{abstract}
A B S T R A C T
Holographic projection is the new wave of technology that will change how we view things in the future; it will have tremendous effects on all fields of life including education and science. Generally, A Hologram is a 3D record of the positive interference of laser light waves. Technology of threedimensional hologram $(3 \mathrm{DH})$ involves spatial displays which detaches the display technology from the user and integrate it into the real environment. This research paper examines the essential information about 3D Hologram technology in or-der to understand the importance of this technology in learning .It highlights uses and advantages of 3D Hologram applications in various fields of education. Overall, this study shows that, 3D Hologram technol-ogy has a positive potential as educational tool and able to catch the students' attention in learning envi-ronment. This paper is valuable for integrating 3D Hologram technology in Libyan higher education institu-tions. The challenges that facing this technology in implementation and the recommendations for future research are addressed at the end of the paper.
\end{abstract}

تقنية الهولوغرام ثلاثية الأبعاد في المؤسسات التعليمية الليبية في المستقبل: مراجعة

$$
\text { *غرسة على المعرش و منى محمد ادراهو انتصار ادريس الجدي علوم الحاسوب، كلية العلوم، جامعة المرقب، ليبيا }
$$

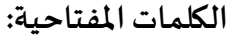

3DH التقنية ثلاثية الأبعاد

التصوير المجسم

التعليم

الإسـقاط الهولوغرافي

التعلم
الملخص

الإسقاط الهولوغرافي هو الموجة الجديدة من التكنولوجيا التي ستغير نظرتنا للأشياء في المستقبل؛ سيكون لها

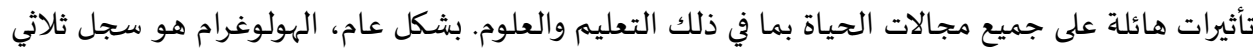

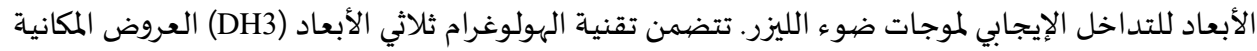

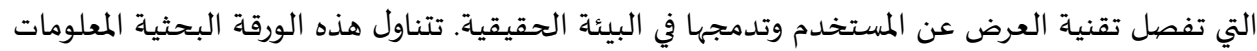
الأساسية حول تقنية الهولوغرام ثلاثية الأبعاد من أجل فهم أهمية هذه التقنية في التعلم، وتسلط الضوء على

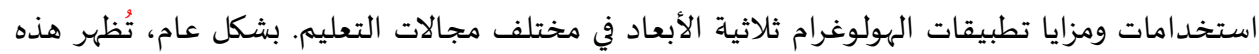
الدراسة أن تقنية الهولوغرام ثلاثية الأبعاد لها إمكانات إيجابية كأداة تعليمية وقادرة على جذب الندان انتباه الطلاب في بيئة التعلم. تعتبر هذه الورقة قيّمة لدمج تقنية الهولوغرام ثلاثية الأبعاد في مؤسسات التعليم العالي الليبية. تم

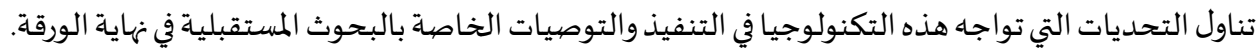

\section{Introduction}

In the past, the traditional model of learning typically characterized as didactic instructions in which information is presented to students, in the traditional learning the teacher is the sole information giver, undertaking lectures for students and the students sitting in the classroom is passive recipients of information. The Information communication technology (ICT) has begun with computer integrated technology to provide knowledge to the students with the help of power point presentation, projector technology in classroom etc. Now, the time has changed such that interactive learning for the students is possible.

Holograms differ from ordinary photographs, because the holograms record an extremely accurate three-dimensional (3D) image of the original object. A hologram is a three dimensional record of the positive interference of laser light waves [1]. The structure of a synthetic hologram is made of thousands of 3D computer graphic images corresponding to as much points of view on a threedimensional scene [2]. Holography takes us a step further by bringing the virtual environment into our physical presence. There are several

*Corresponding author:

E-mail addresses: gharsa.ali@elmergib.edu.ly, (M. M. Adrah) mmadrah@elmergib.edu.ly, (E. E. Eljadi) entisar.eljadi@elmergib.edu.ly Article History : Received 13 December 20 - Received in revised form 06 February 21 - Accepted 11 February 21 
potentials and predictions of how the holography technology can be used as an educational tool in the future [3].

In this paper, we are discussing the use of interactive 3D holographic technology in the classroom in learning. Holography is the only technique that can record the full tri-dimensional quality of an object, and allow the observer to easily see this as an image that is truly 3-D [4]. For instance, holograms of human organs and other figures can be used to teach adults and children simple dissections and health protocols as well as instruct medical students and physicians with the latest surgical techniques, innovative tools and environments. For learners of all ages and backgrounds, tri-dimensional games and systems offer stimulating educational training that can make complex scientific information and health content not only meaningful and instructive but more engaging [5].

This paper is key focus on the level of effectiveness of 3D Hologram as a new tool which could support teaching and learning in educational institutions. For that, the paper aims to understand the importance of 3D Hologram technology in the learning environment, identify the strengths and weaknesses of 3D Hologram technology as a teaching tool and identify the barriers with this technology.

\section{Hologram Technology}

Gabor, who invented holography in 1947, introduced the term using two Greek words: "Holos" - whole and "Graph" -writing. It simply means that the recorded holographic image of the object contains whole optical information about the object - Amplitude and Phase information of the light scattered from the object. Ideally, the hologram is a three-dimensional image reproduced from interference pattern recorded by coherent light beans and holography is a process of reconstructing. Initially, the holograms that were produced were flat two-dimensional transparencies that were obtained from the appropriate considerably coherent light of a sodium vapour lamp. The three-dimensional holograms originated in 1962 with the experiments conducted at the University of Michigan [6] .

The holograms were used in the field of optical engineering that became popular after the World War II. This evolution of holograms continued till today. The hologram has been improved to such an extent that it is possible to project a comprehensive 360-degree holographic display [7].

Hologram is one of the visualization tool that can be referred to as a three-dimensional image [8], created with holographic projection which is are formed by light beams from coherent light like laser light [9]. Hologram are displayed using a technique which is called as holography where it allows light beams from any object to be recorded before reconstructed [10].

Holograms are considered to be truly $3 \mathrm{D}$, because they allow the viewer to see different perspectives of a reconstructed 3D object from different angles and locations [11]. Where holograms differ from photographs is that they are created using lasers, which can produce the complex light interference patterns, including spatial data, required to re-create a complete 3D object [11]. Holograms have which the following essential properties [12]:

a) The light coming from hologram to an eye is physically similar to light coming to the eye looking at the original scene.

b) The standards of 3D Hologram are not in natural colour, but monochromatic at the colour of the reconstructed wave.

c) Cutting a hologram to pieces for reconstruction preserves a whole image.

d) The feeling of 3D vision through a hologram is a real effect, not psychological one.

e) The maximum depth of field that can be seen in a hologram is the function of the coherence length of the laser. The maximum brightness and details that can be seen on the hologram are function of laser.

\section{How Hologram Works}

Holograms are seen from different perspectives when viewed from different angles. This perception of holograms is the same as people view objects in reality. If a hologram is torn into half, each half contains the entire view of the holographic image. In addition, if a hologram of a magnifying glass is made, the holographic magnifying glass is capable of magnifying objects like the real one. Basic tools required to make a hologram includes a red lasers, lenses, beam splitter, mirrors and holographic film [2] as shown in figure 1

The most common type of laser used is helium-neon (HeNe). Even though some holograms are made from diodes from red laser pointers, they are usually unstable and less coherent. Although, holography is generally referred to as "lens-less photography," it requires lenses. In photography, camera lenses usually focus light, contrarily; lenses are used to spread out beamed light in holography. The beam splitter is used to divide a beam of light into two.

The mirrors combined with the lenses and beam splitters are used to direct light to the required locations. In order not to lower the quality of the final image, the mirrors must be free from any form of dirt. The holographic film is capable of recording light in high resolution. Holographic film differs from photographic film because it is capable of recording slight changes in light in microscopic distance [2].

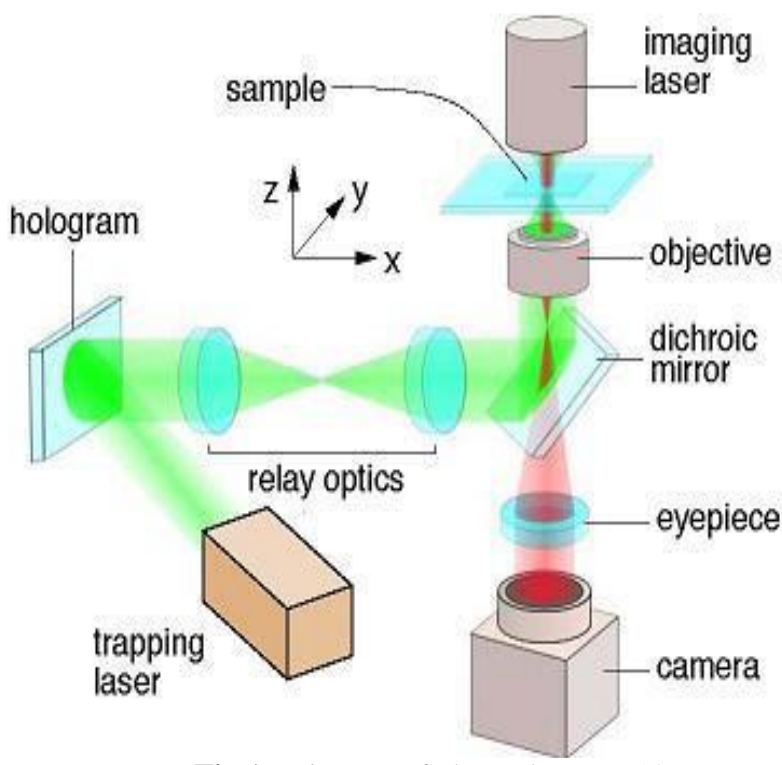

Fig 1 . Diagram of the Hologram [13]

\section{Classification of 3D Holograms}

There are many types of holograms, and there are changeable ways of classifying them. The major types of the hologram are:

\section{Transmission Hologram}

The distinctive transmission hologram is witnessed with laser light, frequently of the same kind used to make the recording. This light is focused from behind schedule the hologram and the image are passing on to the observer's side. The virtual image can be very sharp and deep. For example, through a small hologram, a standard room with people in it can be seen as if the hologram were a window [14]. If this hologram is broken into small pieces (to be less wasteful, the hologram can be covered by a piece of paper with a hole in it), one can still see the entire scene through each piece. Conditional on the site of the piece (hole), a poles apart perspective is observed. In addition, if a diverged laser beam is directed backward (relative to the direction of the reference beam) through the hologram, a real image can be expected onto a screen located at the created position of the object [15] [16].

\section{The Reflection Hologram}

The replication hologram, in which an actually three-dimensional image stays understood nearby surface, stands the extreme public sort showing in galleries. The hologram stays light up in a "spot" of silver optimistic light held on an exact position and distance and expected on the viewer's vexed of the hologram. Thus, the image consisted of light copied in the hologram [14].

Just, these holograms crucial remain complete and showing in colour - their images optically blurry from the exclusive items. If imitate is the object, the holographic image of the glass imitates silver light; if a rhombus is the object, the holographic image of the rhombus is got to "energy." Though mass-produced holograms such as the eagle on the VISA card are gotten with derivative light, they are actually show holograms "looking glass zed" with a layer of 
aluminum on the back [15]. Reflection hologram is the most common type of hologram, it requires the simplest setup and is visible without laser light [16].

\section{The Hybrid Hologram}

As hybrid hologram could be considered a combination of transmission and reflection hologram [14]. Hybrid hologram can be specified as integral holograms, holographic interferometry, multichannel hologram, embossed holograms and computergenerated holograms. For example, embossed holograms are used for authenticity applications such as passports or credit careds. Computer-generated holograms are used to make optical elements, for scanning, in general for controlling laser light [16] [17].

\section{Special Glasses}

This type of glass permits the light to pass through and also permits another light to produce images on the glasses. Microsoft produced Hololens in 2016 [7].This Hololens is the earliest self-contained, holographic computer that aids the user to engross with the digital content and also work together with the other holograms that exists. The Hololens is Microsoft's take on augmented reality, which they call "mixed reality". Using multiple sensors, advanced optics, and holographic processing that melds seamlessly with its environment, These holograms can be used to display information, blend with the real world, or even simulate a virtual world [18].

\section{Applications and Advantages of 3D Hologram Technology in}

\section{Education}

Recently, technology introduces new educational applications and gives new meaning to the learning process. Especially what the 3D Hologram technique now offers in various subjects of science and training programs to consider it as a good means of teaching. It can be said that the fact of being able to observe an image in three dimensions is motivating in itself. The student has the feeling that this object is present and feels more predisposed towards learning.

The following research paper discusses the idea of creating an interactive hologram in education in various fields (Table 1).

\section{Table 1. Applications and Advantages of 3D Hologram Technology in Education}

\begin{tabular}{cc}
\hline Field & Study \\
& {$[19][20]$} \\
& {$[21][22]$} \\
& \\
Medicine & {$[23]$} \\
$\boldsymbol{\&}$ & \\
Nursing: & {$[6][24]$} \\
& {$[25][26]$}
\end{tabular}

Science Subjects:

Engineering (Graphics and Drawing)

$$
\text { \& }
$$

Aeronautical

Engineering:

Architectural

Engineering:

Pharmacology:

Distance
Education:
Children Learning
Process:
History and
Archeology:

\section{Uses and advantages of 3D Hologram application}

3DH technology allow students to interact with a realistic hologram of an organ or body

it would enhance their comprehension and learning process. With this technology medical students could perform surgeries on a $3 \mathrm{DH}$ without the risk of harming a real human, which is be a clear benefit to educational society.

NYU School of Medicine has introduced the Bio Digital Human, an online 3D interactive medical visualization program. Wearing $3 \mathrm{D}$ glasses, students can view and explore lifesize $3 \mathrm{D}$ virtual human body projected on a $2 \mathrm{D}$ projector screen, magnifying and dissecting organs and anatomic structures .ex: as shown in figure 2.

In the study the cardiovascular structure of heart was developed using the $3 \mathrm{D}$ scanning method . the image was converted into a $3 \mathrm{D}$ vector layer object and then segmented into different images with different viewing angles to produce a 3D floating image. There are some hologram systems that have been developed by companies for medical area, such as EchoPixel True 3D, and HoloPaint.

The research has designed a technological tool that improves meaningful learning in the teaching of science subjects.

holograms help to understand the contents of science better due to the fact that its movement in three dimensions draws more attention.

If a $\mathrm{n}$ engineering lecture wants to explain about the internal structure of an internal combustion engine to the students, it is highly difficult to haul the engine to the classroom and lift the engine up in the class in order to elaborate about the internal parts of the engine as highlighted in figure 3 .

Can use the hologram to display the 3D imaging building to students. There are some hologram systems were built for the architecture for instance, Zebra Imaging System. 3D Hologram technology helps student to comprehend clearly on how drugs work and affect the human body through displaying internal organs of human body that show drugs movement.

The Hologram can be used to increase interaction in the distance learning programs to reinforce the professional skills of students and achieve the maximum benefits for them.

3D Hologram technology has a positive potential and able to catch the children'attention in learning as well as reduce their cognitive load.

3D Hologram can bring things such as characters,

virtual teacher and archaeological findings to be on live. Also 3D Hologram enhance oral history's claim to truth and historical indexicality in a way that 2D cannot achieve.

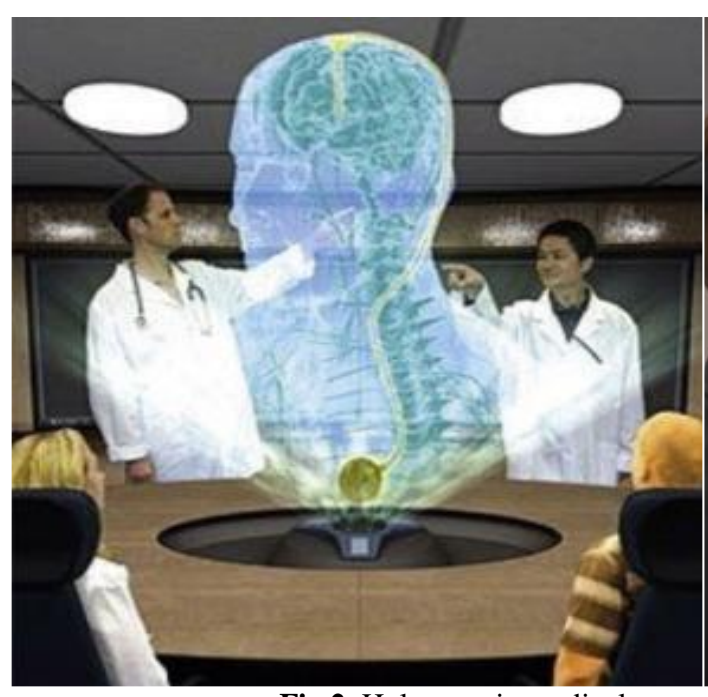

Fig 2. Hologram in medical science [27]

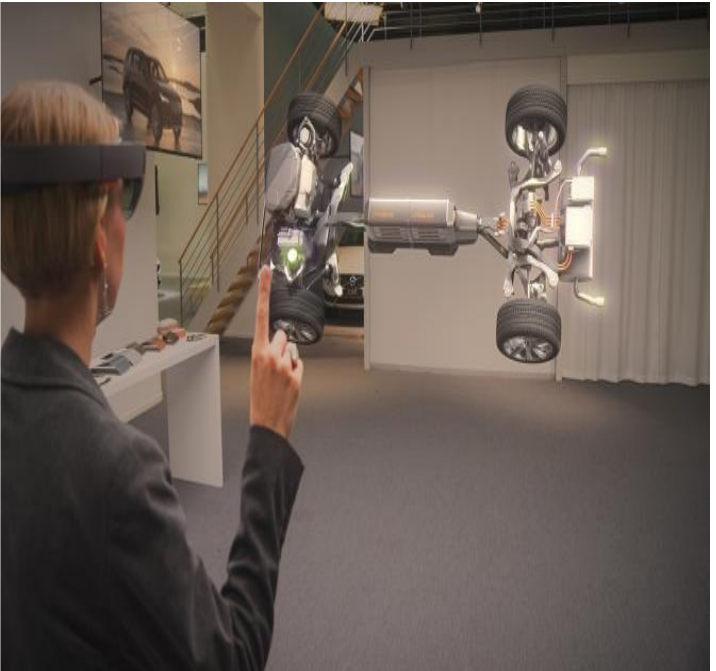

Fig 3. Classroom demonstration using Microsoft Hololens [42] 


\section{A future Prospective of Holography in Libyan Higher \\ Education}

The advantages offered by ICT in education sector have led many educational institutions to integrate ICT services into their respective academic departments especially in the advanced societies and few third world countries. These rapid developments result tremendous changes in many fields and endeavors of life education inclusive. Therefore, educational institutions quickly took advantages of constructivist technological services by integrating ICT into education, which in turn has produced new models of education such as eLearning, m-learning, interactive learning and blended learning. In the field of education, the hologram is very importance. The reason is that students can actually view the concepts that are taught and visualize them during class and is effective tool in theoretical and practical content delivery in classrooms [43]. Moreover, Libya is a country interested in investing in the next generation of technology. 3D Holographic imaging is an ideal investment that can facilitate classroom learning [44] .For instance, Artificial Intelligence is fast becoming a world reality. Therefore, holograms installation and cost implications could strike a breakthrough with artificial intelligence. The critical consideration would be installing the technology at present, or giving it time for more advancement, creating a 10 -year implementation plan for example.

In addition, the technology can be implemented in distance learning, giving students enrolled in such programs an opportunity to study in real classes miles away from their classrooms .

The use of 3D Hologram technology in educational institutions in student learning is in its initial phases. Therefore, the technology should be implemented in a location full of professionals and with adequate resources. The resources are fast speed internet access, financial endowment, and equipment availability. Moreover, before purchasing and investing in the implementation of technology, Libyan education institutions can get comprehensive information about the technology's cost parameters and installation procedures from companies dealing with installations, such as Virtual-On [45]. After that these institutions could draft a proposal to the Libyan government through the ministry of education requesting funding. The proposal should include the equipment costs, labor costs, and the costs of installation.

On the other hand, holographic technologies are not just about a business communication, they are about safety, security, and strength of our civilization here and beyond. All these are yet to be adequate in my country Libya. In additional, there are major barriers in implementing 3D hologram technology in Libyan education such as : lack of so many infrastructural and technological facilities in most high education institutions in the country, limited bandwidth, recurrent power cuts, lack of technical Know and laking of technical experts.

Finally, Libyan educational institutions (from elementary to school to the universities) ought to invest in research and include the technology in the learning of the students specifically, within the school curriculum. This technology will helps them to clarify the concepts in abetter manner and will enhance the way students learn.

\section{Disadvantages of 3D Hologram Technology Application in}

\section{Education}

As any technology, 3DH has some disadvantages including:

Firstly, prolonged use in the classes of these technology can have negative repercussions at the visual level and loss of consciousness, meaning that for students with vision or neurological problems is not very suitable to use this type of tool in a prolonged way $[23,46]$. Also, the quality of $3 \mathrm{D}$ renderings is a significant concern in instructional effectiveness in many disciplines, including engineering and medicine since many of the applications used do not offer the sufficient quality [23].

\section{Challenges of 3D Hologram Technology Implementation}

- Although 3DH technology could offer enrichment in learning environments, there are also challenges that may hinder implementation in many educational environments such as:

- Cost, although the prices of light modulators and other components have lowered in recent years, the cost of producing holograms at a big scale remains enormous[40].
- 3DH technology needs to be connected to a fast Internet, nextgeneration broadband Inter-Network with a minimum guaranteed constant speed of 20 megabits per second.

- To use this technology perfectly, we will need a screening room with compatible lighting and video technology, which costs around 150,000 US dollars to install, as well as a display screen for viewing the holograms on [41].

- The personnel handling the equipment needs heightened skills in the field of information technology.

- Designers will have to come up with innovative ways in which Conclusion

Although holography is very expensive and difficult to integrate with the learning environment, it is of much very interesting to use this technology in the teaching process even if it is expensive to implement at present. The results of all articles reviewed have proved the significant of 3D Hologram as an effective tool for classroom. Meanwhile, the using of 3D hologram technology visualisation skill is important for students to develop abstract imagination of objects or concepts; it can help students improve their perception in order to understand the concept of learning topics, especially in medical and engineering sector as they get to have a better understanding of what they are learning. We can apply 3D Hologram technology in each level of education (preschool, primary and secondary school, and higher education). This can overcome the problem of slow adaption of the technology in education system.

\section{Recommendations}

The phenomenon should lead other researchers to:

- Investigate whether holography will be an effective tool for the teacher's in the future.

- Explore in depth about identifying the suitable techniques of 3DH that can increase students' understanding.

- Assessing the educators and students' acceptance toward 3DH application during teaching and learning session due to the research on this teaching tool are still lacking in context of education.

\section{References}

[1]- A. H. Awad and F. F. Kharbat, "The first design of a smart hologram for teaching," in 2018 Advances in Science and Engineering Technology International Conferences (ASET), 2018, pp. 1-4.

[2]- https://science.howstuffworks.com/hologram.htm.

[3]- O. Aina, "Application of holographic technology in education," 2010.

[4]- K. Ko, "Superimposed holographic image-guided neurosurgery," Journal of neurosurgery, vol. 88, pp. 777-781, 1998.

[5]- R. A. Walker, "Holograms as teaching agents," in Journal of Physics: Conference Series, 2013, p. 012076.

[6]- Y. M. Chang and C. L. Lai, "“Floating heart" application of holographic 3D imaging in nursing education," International Journal of Nursing Education, vol. 10, pp. 25-30, 2018.

[7]- R. Kerstein, "Life through a HoloLens," The Bulletin of the Royal College of Surgeons of England, vol. 100, p. 333, 2018.

[8]- S. Ahmad, "Holography in the nigerian education system: readiness for a redress," in International Conf. on Humanities Sciences and Education (ICHE 2014), 2014, pp. 291-310.

[9]- U. Sudeep, "Use of 3D hologram technology in engineering education," in Jaysingpur, editor. Second Int. Conf. Emerg. Trends Eng., IOSR Journal of Mechanical and Civil Engineering, 2013, pp. 62-7.

[10]- A. Ratan, Holography - Working Principle and Applications, 2015.

[11]- https://phys.org/news/2015-02-high-resolution-full-colorholograms-d.html.

[12]- S. Raza and S. Sharma, "Holography: A Review," International Journal of Applied Physics and Mathematics, vol. 2, p. 184, 2012.

[13]- S. A. Ahmad, I. M. Abdullahi, and M. Usman, "General Attitude and Acceptance of Holography in Teaching among 
Lecturers in Nigerian Colleges of Education," IAFOR Journal of Education, 2015.

[14]- T. H. Jeong, "Basic principles and applications of holography," Fundamentals of Photonics, pp. 381-417, 2010.

[15]- M. K. M. T. G. Priyadharshini, "7D Holographic Projection Display Technologies."

[16]- J. Matišák, M. Rábek, and K. Žáková, "Use of Holographic Technology in Online Experimentation," in 2019 Federated Conference on Computer Science and Information Systems (FedCSIS), 2019, pp. 921-924.

[17]- A. Jeong and T. Jeong, "What Are the Main Types of Holograms?," Integraf LLC, 2019.

[18]- https://www.gvsu.edu/cms4/asset/7E70FBB5-0BBC-EF4CA56CBB9121AECA7F/7_things_about_microsoft_hololens.p df.

[19]- T. Sano, "Holography: The Next Disruptive Technology," ARMY RESEARCH LAB ABERDEEN PROVING GROUND MD ABERDEEN PROVING GROUND United ...2017.

[20]- S. Yamada, T. Kakue, T. Shimobaba, and T. Ito, "Interactive holographic display based on finger gestures," Scientific reports, vol. 8, pp. 1-7, 2018.

[21]- J. Zhang, J. Sun, Q. Chen, J. Li, and C. Zuo, "Adaptive pixelsuper-resolved lensfree in-line digital holography for wide-field on-chip microscopy," Scientific reports, vol. 7, pp. 1-15, 2017.

[22]- Y. Wu, Y. Luo, G. Chaudhari, Y. Rivenson, A. Calis, K. De Haan, et al., "Bright-field holography: cross-modality deep learning enables snapshot 3D imaging with bright-field contrast using a single hologram," Light: Science \& Applications, vol. 8, pp. 1-7, 2019.

[23]- H. Lee, "3D holographic technology and its educational potential," TechTrends, vol. 57, pp. 34-39, 2013

[24]- T. Thap, Y. Nam, H.-W. Chung, and J. Lee, "Simplified 3D Hologram Heart Activity Monitoring Using a Smartphone," in 2015 9th International Conference on Innovative Mobile and Internet Services in Ubiquitous Computing, 2015, pp. 447-451.

[25]- J. Song, C. L. Swisher, H. Im, S. Jeong, D. Pathania, Y. Iwamoto, et al., "Sparsity-based pixel super resolution for lensfree digital in-line holography," Scientific reports, vol. 6, p. 24681, 2016.

[26]- F. Merola, P. Memmolo, L. Miccio, R. Savoia, M. Mugnano, A. Fontana, et al., "Tomographic flow cytometry by digital holography," Light: Science \& Applications, vol. 6, pp. e16241e16241, 2017.

[27]- S. Mishra, "Hologram the future of medicine-From Star Wars to clinical imaging," Indian heart journal, vol. 69, p. 566, 2017.

[28]- L. Orcos, N. Arís, C. E. Fernández, and Á. A. Magreñán, "Holographic Tools for Science Learning," in International Workshop on Learning Technology for Education in Cloud, 2017, pp. 36-45.

[29]- A. Khan, S. Mavers, and M. Osborne, "Learning by Means of Holograms," in Society for Information Technology \& Teacher Education International Conference, 2020, pp. 1134-1139.

[30]- M. P. Arnone, R. V. Small, S. A. Chauncey, and H. P. McKenna, "Curiosity, interest and engagement in technologypervasive learning environments: a new research agenda," Educational Technology Research and Development, vol. 59, pp. 181-198, 2011.

[31]- Z. Imaging, "Zebra Imaging Announces Sale of 3D Holographic Print Assets to HoloTech Switzerland AG," CISION: PR Newswire, vol. 26, 2017.
[32]- D. Freeman, "Holographic MRI and CT scans of the human body," Styiles Inc. the Prototypes Design Group, 2010.

[33]- M. Abdelhamid, "Using 3D Hologram Technology (3DHT) in the Distance Learning Program to Enhance the Professional Skills of Tour Guidance Undergraduate Students," Journal of Association of Arab Universities for Tourism and Hospitality, vol. 18, pp. 17-34, 2020.

[34]- P. Kalansooriya, A. Marasinghe, and K. Bandara, "Assessing the Applicability of 3D Holographic Technology as an Enhanced Technology for Distance Learning," IAFOR Journal of Education, 2015.

[35]- G. Tonguç and Ö. Ü. B. Ö. ÖZKARA, "Using 3d Hologram in Distance Education," Türkiye Eğitim Dergisi, vol. 5, pp. 56-68.

[36]- K. L. Pradeep, "A Study on Enhancing Virtual Reality Visualization with Hologram Technology and Bio-signal Interactive Architectures," ed: Nagaoka University of Technology, 2016.

[37]- N.-H. Loh and S. S. B. Shaharuddin, "CORPORATE SOCIAL RESPONSIBILITY (CSR) TOWARDS EDUCATION: THE APPLICATION AND POSSIBILITY OF 3D HOLOGRAM TO ENHANCE COGNITIVE SKILLS OF PRIMARY SCHOOL LEARNERS," International Journal of Business \& Society, vol. 20, 2019

[38]- L. N. Hoon and S. S. Shaharuddin, "Learning effectiveness of 3D hologram animation on primary school learners," Journal of Visual Art and Design, vol. 11, pp. 93-104, 2019.

[39]- N. M. M. Barkhaya and N. D. Abd Halim, "A review of application of 3D hologram in education: A meta-analysis," in 2016 IEEE 8th International Conference on Engineering Education (ICEED), 2016, pp. 257-260.

[40]- C. R. Ramachandiran, M. M. Chong, and P. Subramanian, "3D hologram in futuristic classroom: a review," Periodicals of Engineering and Natural Sciences, vol. 7, pp. 580-586, 2019.

[41]- H. Ghuloum, "3D hologram technology in learning environment," in Informing Science \& IT Education Conference, 2010, pp. 693-704.

[42]- S. Erickson, "Microsoft HoloLens and Volvo Cars explore the future of car buying," ed: Microsoft. November, 2015.

[43]- J. N. Bailenson, N. Yee, J. Blascovich, A. C. Beall, N. Lundblad, and $\mathrm{M}$. Jin, "The use of immersive virtual reality in the learning sciences: Digital transformations of teachers, students, and social context," The Journal of the Learning Sciences, vol. 17, pp. 102-141, 2008.

[44]- J. L. Perdomo, M. F. Shiratuddin, W. Thabet, and A. Ananth, "Interactive 3D visualization as a tool for construction education," in 2005 6th International Conference on Information Technology Based Higher Education and Training, 2005, pp. F4B/23-F4B/28.

[45]- A. Rizzo, D. Klimchuk, and R. Mitura, "The Virtual Classroom: A Virtual Environment for the Assessment of Attention Processes in Children with Attention Deficit Hyperactivity Disorder," in Virtual Reality for Public Consumption, IEEE Virtual Reality 2004 Workshop, Chicago IL, 2004

[46]- S. Nichols and H. Patel, "Health and safety implications of virtual reality: a review of empirical evidence," Applied ergonomics, vol. 33, pp. 251-271, 2002. 